\title{
Development of Shape Process Control System in Hot Strip Mill
}

\author{
Zi-Ying Liü ${ }^{1, a}$, Ying-Ping Guan ${ }^{2, b}$ and Feng-Qin Wang ${ }^{1, c}$ \\ ${ }^{1}$ Shougang Research Institute of Technology, Beijing 100043, China \\ ${ }^{2}$ Graduate School of Yanshan University, Qinhuangdao 066004, China \\ azoonlzy@163.com, byyp@ysu.edu.cn, cwangfengqin@shougang.com.cn
}

Keywords: Process control system, profile and flatness, hot strip mill.

\begin{abstract}
In the process of hot strip rolling, accurate and efficient shape process control system is an important factor to ensure strip with good shape. This paper, based on advanced control concept and optimization mathematical model, aimed at Jingtang 1580 hot strip rolling project, developed advanced shape control system. Among them, the HPCS process control platform and HPFC shape control system is designed, they are the basis of the shape control system; the control strategy based on the buckling limits is optimized ,it is the key to shape control system; the mathematical model is the core of strip shape control system. The system and related research achievement has been applied in Jingtang 1580 hot strip rolling project, in the thickness of $1.2 \mathrm{~mm}$ to $12.7 \mathrm{~mm}$ strip production, shape control achieved good results.
\end{abstract}

\section{Introduction}

The objective of the profile control system is to achieve mill exit thickness profiles and strip flatness within specification whilst maintaining acceptable inter-stand strip flatness free from visible buckling and mill operation which avoid cobbles [1,2]. The exit strip flatness is important for the successful transport of the strip head end along the run out cooling table and for optimum coiling and downstream processing. For a long time, the shape process control system in hot strip rolling had been imported from abroad [3, 4]. In recent years, the many domestic units had done a lot of work on the strip shape process control system, and had been developed process control systems used successfully in the production practice [5, 6]. But there are still many problems needing further research in the shape process control.

Based on the project of Jingtang 1580mm hot strip rolling project, this paper has researched and developed shape process control system, including the development of process control platform, shape process control system composition, shape process control strategy, etc. The system and related research achievement has been applied in Jingtang 1580 hot strip rolling project, in the thickness of $1.2 \mathrm{~mm}$ to $12.7 \mathrm{~mm}$ strip production, shape control achieved good results, the development of shape process control system has practical significance to improve the quality of strip shape.

\section{Process Control Platform}

HPCS process control platform is developed. HPCS is mainly to complete data acquisition, communications, simulation of rolling, tracking and logic control, etc. as shown in Fig.1. 


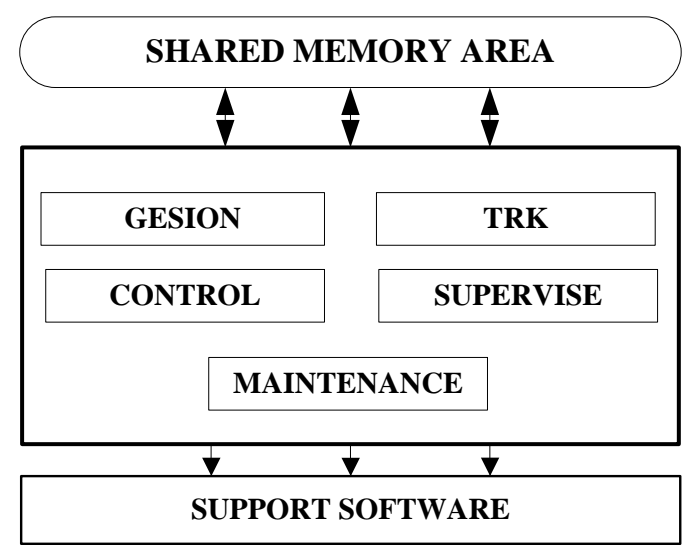

Fig.1 The Structure of HPCS Platform

The shape process control platform is composed of following five subsystems: communication subsystems (GESIOS), rolling piece tracking subsystem (TRK), rolling control subsystem (CONTROL), monitoring subsystem (SUPERVISE), maintenance subsystem (MAINTENANCE). Among them, GESIOS system is responsible for data communication of the platform with PLC, HMI, TRK system is responsible for tracking rolled piece, CONTROL system is responsible for finishing rolling control, SUPERVISE system is responsible for completing supervising process, MAINTENANCE system is responsible for system platform operation and maintenance.

Fig. 2 is the flow chart of major events for the process e control platform. Among them, the data center is mainly to complete the slab yard management, end product management and roll management, and to form the corresponding data packet for shape model called; communication module is to complete instruments, PLC and HMI communication work, and the corresponding data is send to the data pack module and logic control module; logic control module is to complete triggering the corresponding model calculation according to the tracking logic signal; modules can be simulated with the help of simulation module. Only these modules can be methodical start-up, operation, data acquisition, data storage, and so on, the process shape control system can accurately and efficiently in calculating.

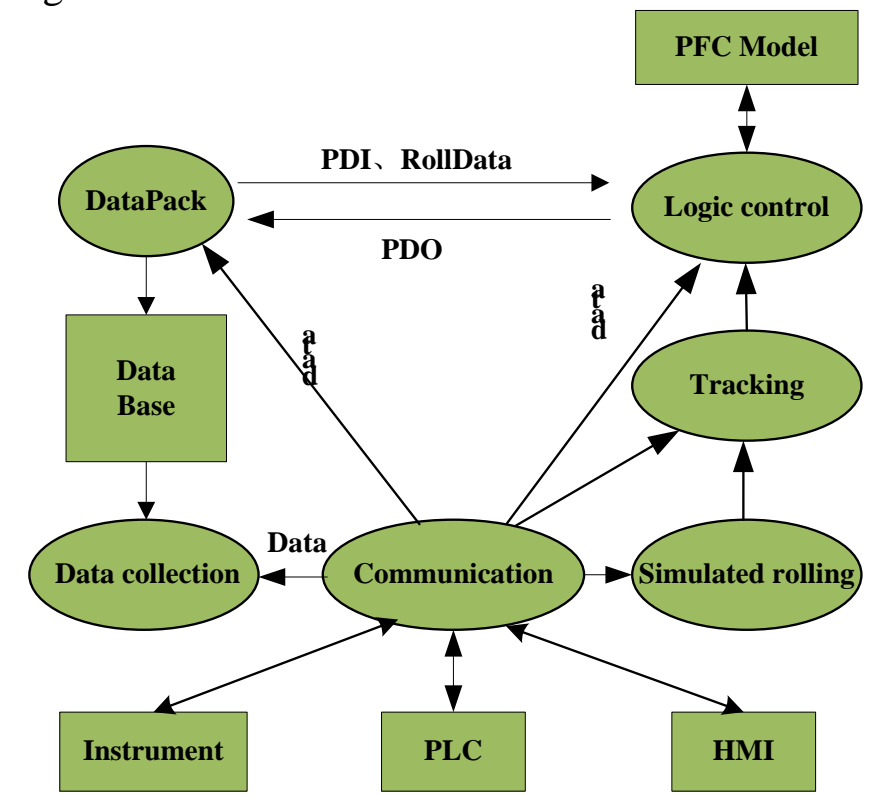

Fig.2 The Flow Chart of Major Events about HPCS System

\section{Control System.}

The objective of the shape process setup calculation is to supply all of the information required by the dynamic mill control system, to achieve and maintain the target exit profile and flatness as well as 
the inter-stand flatness. The setup algorithm is illustrated in Fig.3. The finishing mill entry profile1 $H_{1}(x)$ is then calculated as:

$$
H_{1}(x)=\hat{h}_{R n}(x)+\Delta \hat{H}_{1}^{a}(x)
$$

Where, $\hat{h}_{R n}(x)$ is the predicted loaded roll gap profile, $\Delta \hat{H}_{1}^{a}(x)$ is the entry profile adaptation term determined by observation of the finishing mill exit profile. The natural output profile is that which would be produced by the mill, for the given incoming profile, if conditions of perfect flatness are maintained in all inter-stand and mill exit sections. The natural output profile is calculated as:

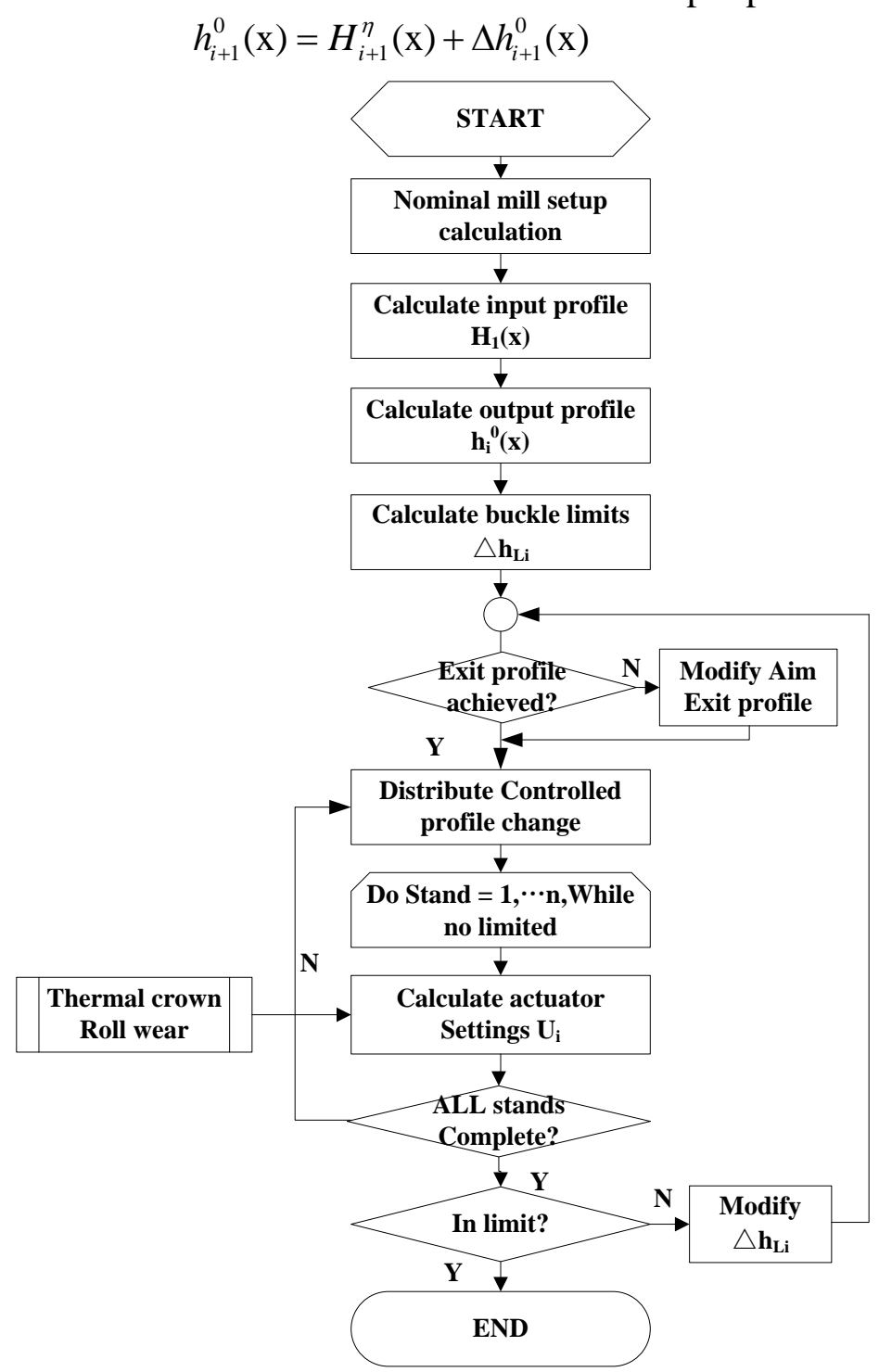

Fig.3. The Setup Algorithm

Where, $H_{i+1}^{\eta}(x)$ is the corrected natural profile entering stand $\mathrm{i}+1, \Delta h_{i+1}^{0}(\mathrm{x})$ is natural thickness profile change on stand $\mathrm{i}+1$, the formulas are as follows:

$$
H_{i+1}^{\eta}(x)=h_{i}^{\eta}(x)+f_{C}\left(\theta(X, Z), t_{S i}^{\eta}(x)\right)
$$

where, $f_{C}$ is the inter-stand creep model function; $h_{i}^{\eta}(x)$ is the thickness profile at stand $i$ exit; $\theta(X, Z)$ is the strip temperature distribution between stands $i$ and $i+1 ; t_{S i}^{\eta}(x)$ is expected total stand exit tension stress. $h_{i}^{\eta}(x)$ is calculated by the equation as following:

$$
\left\{\tilde{u}, h_{i}^{\eta}(x), P_{i}^{\eta}(x)\right\}=f_{R S D}\left(h_{i}^{0}(x), y_{m}(x), P_{i}^{0}(x), K_{S}\right)
$$


where, $h_{i}^{0}(x)$ is the initial natural exit thickness profile; $y_{m}(x)$ is a vector of roll mechanical profiles reflecting the effects of roll grind, thermal camber and roll wear; $P_{i}^{0}(x)$ is the natural specific roll force; $K_{S}$ is the strip stiffness sensitivity influence function, $f_{R S D}$ is RSD model, and $P_{i}^{\eta}(x)$ is optimized specific force.

The total profile control change can then be distributed across the available profile control stands in proportion to the buckling limits on the stand using the equation:

$$
\Delta h_{c i}=c_{p m} \times\left[\frac{\Delta h_{L i}}{\Delta h_{C L}^{T}}\right] \times \Delta h_{C}^{* T}
$$

Where, $c_{p m}$ is the coefficient; $\Delta h_{L i}$ is the buckle limits on stand I, $\Delta h_{C L}^{T}$ is the maximum controlled profile change; $\Delta h_{C}^{* T}$ is the amplitude of the desired control change.

Summing with the pressure profile previously calculated for the actual natural profile $P_{i}^{\eta}(x)$ provides the required pressure profile for the solution of the roll stack deflection actuator optimization for the stand in equation:

$$
P_{i}(x)=P_{i}^{\eta}(x)+\Delta P_{C i}(x)
$$

Depending upon the stand configuration, optimum roll bending forces and side-shift settings may then be obtained using a roll stack deflection model. This calculation is performed for the different roll thermal conditions present. Based on these results, a trajectory is derived for the compensating flatness actuator changes to be applied as the coil is rolled. Having previously noted the thermal camber and wear amplitudes at the various simulation result points through the coil, the change in thermal camber for the coil start can be multiplied with the bending sensitivity to thermal camber to produce the anticipated bending trajectory for thermal compensation through the coil. The actuator optimization and roll thermal camber compensations are then calculated in the algorithm.

\section{Application}

The shape process control system is applied Jingtang 1580mm hot strip rolling project, good results have been achieved. Along the strip length direction, we measured the crown deviation and flatness deviation every two meters, the number of all points is 50, crown deviation and flatness deviation is shown in Fig.4. We can see that the crown deviation is in the range of $-20 \mu \mathrm{m}$ to $20 \mu \mathrm{m}$, the flatness deviation is in the range of -15I to 15I. The chart shows that the process control system for Jingtang $1580 \mathrm{~mm}$ strip rolling achieved good control effect.
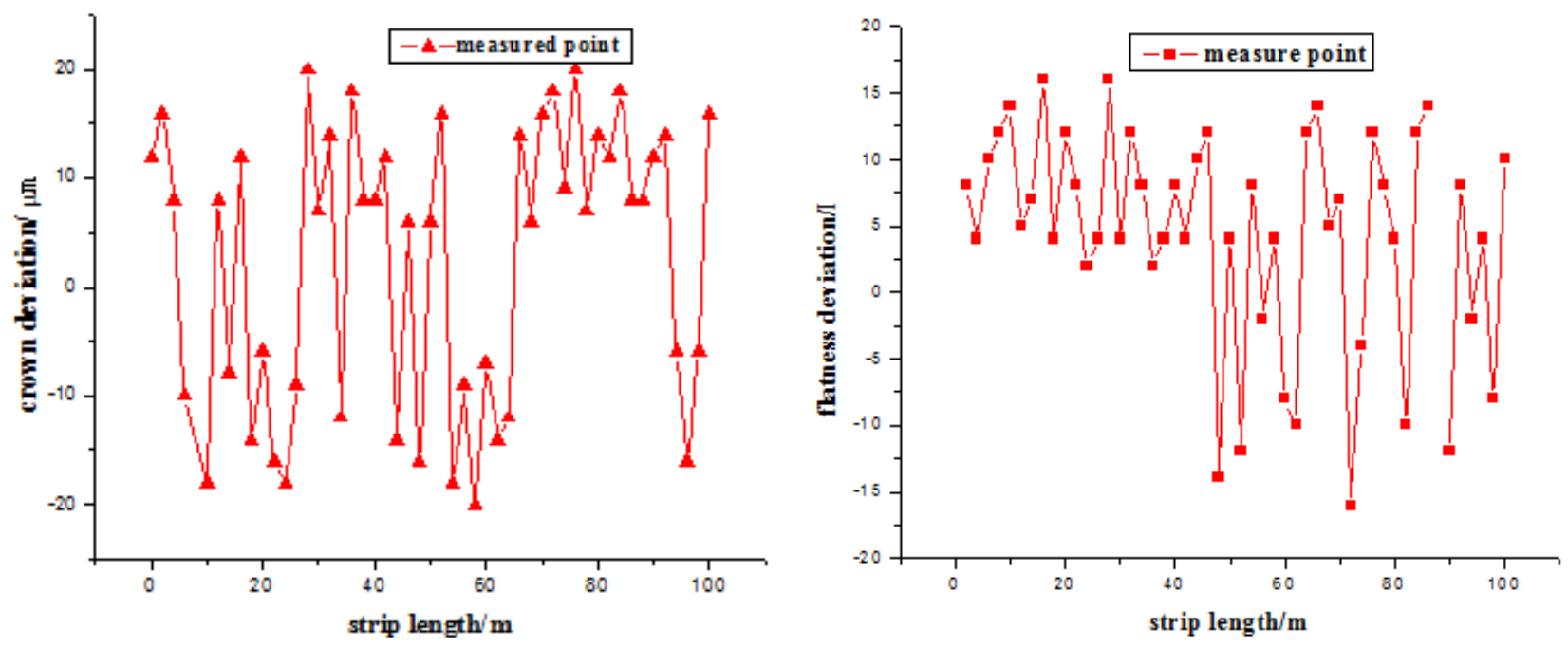

Fig.4: The Crown Deviation 


\section{Conclusions}

This paper, based on advanced control concept and optimization mathematical model, aimed at Jingtang 1580 hot strip rolling project, developed advanced shape control system. Among them, the HPCS process control platform and HPFC shape control system is designed, they are the basis of the shape control system; the control strategy based on the buckling limits is optimized, it is the key to shape control system; the mathematical model is the core of strip shape control system. The system and related research achievement has been applied in Jingtang 1580mm hot strip rolling project, in the thickness of $1.2 \mathrm{~mm}$ to $12.7 \mathrm{~mm}$ strip production, shape control achieved good results.

\section{Acknowledgments}

This work was financially supported by Beijing postdoctoral research fund 2015 ZZ-152.

\section{References}

[1] XIE Hai-bo, XU Xu-dong, LIU Xiang-hua, Numerical Simulation on Hot Strip Temperature Field in Laminar Cooling Process, Journal of Iron and Steel Research. 2005, Vol.17, No.4, 33.

[2] WANG Ying-rui, YUAN Jian-guang, LIU Hong-min, Shape Control Simulation on 4-High CVC Mill, JournaI of Iron and Steel Research, International. 2005, Vol.12, No.2, 25-32.

[3] WANG Wen-ming, ZHONG Jue, TAN Jian-ping, Development of Strip Shape Control Theory and Technique, Mining and Metallurgical Engineering. 2001, Vol.21, No.4, 70-72.

[4] MEI Rui-Bin, LI Chang-sheng, LIU Xiang-hua, et al, Analysis of Strip Temperature in Hot Rolling Process by Finite Element Method, Journal of Iron and Steel Research. 2010, Vol.17, No.2, 17.

[5] Archard JF, Rowntree RA, The Temperature of Rubbing Bodies. II. The Distribution of temperatures, Wear. 1998, 128(1): 1-17.

[6] Sauer W, Thermal camber model for hot and cold rolling, Steel Research. 1996, 67(1):18 -21. 